\title{
RELAÇÕES SOCIAIS: AS TROCAS E OS MITOS DE UM MUNDO SEM TROCAS
}

\author{
José Newton Garcia de Araújo ${ }^{1}$ \\ Pontíficia Universidade Católica - Minas Gerais
}

\begin{abstract}
Neste ensaio, discute-se o fenômeno da troca como a instituição que funda o nascimento da cultura e das relações sociais. A busca de compreensão deste fenômeno se baseou na análise de dois momentos mítico-teóricos nos quais as formas de interação são marcadas pela ausência das trocas: de um lado, os conceitos operatórios que se referem a um estágio pré-cultural da humanidade, evocados distintamente por Hobbes e por Freud, num contexto de pura violência; de outro lado, a invenção da idéia de gratuidade, o que supõe a impossibilidade da reciprocidade, dada a desigualdade estrutural entre as partes em interação. Apesar de as trocas serem analisadas como o fundamento maior das relações sociais, típicas dos estágios avançados da cultura, isso não evita que também elas sejam, quase sempre, marcadas pela desigualdade e permanentemente atravessadas pela irrupção de conflitos. Estes, no entanto, são tomados como um elemento essencial para o desenvolvimento da cultura e para a dinâmica das relações sociais.
\end{abstract}

Descritores: Interação social. Violência. Conflito.

To presente ensaio, tomamos como objeto de discussão o tema da troca. 1 Este termo pode remeter, à primeira vista, ao cenário das relações econômicas. Concordamos com esta concepção, se considerarmos que a noção de economia é polissêmica e que a prática das trocas não se aplica apenas à

1 Mestre em Filosofia pela Universidade Federal de Minas Gerais e doutor em Psicologia pela Universidade de Paris 7. Docente do Instituto de Psicologia da PUC-Minas Gerais. Endereço para correspondência: Rua Grão-Pará, 1060 - 101. CEP 30150-341. Belo Horizonte, MG. Endereço eletrônico: jinga@uol.com.br 
chamada economia de mercado, regida pela ideologia da acumulação, do lucro ou do cálculo mercantilista. Meillassoux (1985) escreve que a idéia de troca se aplica, genericamente, a todo movimento de intenção recíproca entre duas partes. Seguindo esta trilha, vamos avançar na hipótese de que as relações de troca permeiam todas as atividades humanas ditas civilizadas, seja no âmbito maior das relações entre nações, coletividades e instituições, seja nos microespaços das relações entre indivíduos e pequenos grupos. Nesse último caso, podemos nos referir às microeconomias que regem, por exemplo, as trocas de favores, de presentes, de saberes, de informações, de afetos. Ainda num sentido amplo, pode-se dizer que é a instituição das trocas que marca a passagem da barbárie à civilização, ou seja, são elas que presidem ao nascimento da cultura humana e sustentam a dinâmica das relações sociais. Voltaremos, mais adiante, a esta questão.

Neste estudo, apoiamo-nos nos textos de autores que, como Mauss (1908/1974), vêem a troca como um fenômeno universal, inerente à natureza humana e presente em todas as sociedades, sejam elas arcaicas ou contemporâneas. Quando se toma a idéia de troca apenas no plano da economia de mercado, a hipótese de sua universalidade se reduz e até se faz objeto de controvérsias históricas, já que as transações mercantis só atingem seu pleno desenvolvimento com o advento do capitalismo. Meillasssoux (1985) comenta, por exemplo, que nas sociedades primitivas, os produtos do trabalho coletivo, na colheita ou na caça, eram repartidos entre seus membros, sem que isso implicasse, forçosamente, a obrigação de contrapartida entre produtores e não-produtores. Com efeito, as trocas de mercadorias e serviços, baseadas em relações contratuais, só aparecem em função da ocorrência histórica dos excedentes da produção, da divisão do trabalho, da propriedade privada e assim por diante. Mauss (1908/1974, p. 176) também comenta que "foram nossas sociedades ocidentais que, muito recentemente, fizeram do homem um 'animal econômico'.”

Cabe, então, perguntar-nos sobre o alcance da noção de troca, uma vez que, tanto nas sociedades primitivas quanto nas atuais, as transferências de bens materiais e simbólicos, assim como suas contrapartidas, ocorrem também no plano informal das relações comunitárias, familiares ou das de- 
pendências interpessoais. Assim, nossas relações cotidianas são permeadas por miríades de pequenos serviços e bens transferidos a outrem, com retribuições que escapam à racionalidade das transações jurídicas e comerciais. Temos, pois, de recorrer a outros parâmetros interativos ou relacionais, quando nos referimos, por exemplo, à economia pulsional ou às trocas afetivas, no campo "psi”. Ou no terreno religioso, quando falamos da economia do sacrifício, em troca das graças divinas. Ou ainda nos afazeres cotidianos, em que lidamos continuamente com a economia do tempo ou das energias física e psíquica, numa espécie de barganha conosco mesmos.

Em todos esses "regimes econômicos" a troca é o elemento central, tendo a sua "moeda" diversas caras, conforme seu uso comercial, religioso, científico, político ou amoroso. E mais: se a instituição da troca supõe uma prestação e uma contraprestação, isso implica, para cada uma das partes, algum tipo de interesse e de ganhos, materiais ou imateriais, visíveis ou invisíveis, imediatos ou presumíveis.

As considerações acima podem, no entanto, perder-se num vácuo teórico e reflexivo, se entendermos as dinâmicas macro e microssociais como um sistema funcional de trocas, regido por uma reciprocidade harmoniosa entre as partes. Seria cômodo, por exemplo, ficarmos com a definição de Knight (1959, citado por Perroux, 1960, p. 149), para quem a troca implica uma transferência voluntária, com vantagens recíprocas de objetos ou serviços, numa “...equivalência fundamental entre as coisas trocadas, uma igualdade em valor que assenta na racionalidade econômica e nas instituições do mercado desenvolvido."

Não vamos discutir aqui a irracionalidade da "racionalidade econômica”, que produz sistemas de troca estruturalmente perversos e desiguais, produz violências instituídas ou impostas, desembocando, muitas vezes, na eliminação mesma das trocas. Mas se estas, como vimos, não se restringem à economia de mercado, vale assinalar que suas formas perversas ou sua anulação se estende a todas as "economias”, ou seja, ao conjunto das relações sociais, políticas, econômicas, religiosas, étnicas, familiares, de gênero, além de muitas outras. 
Nesse caso, cabe observar que a expressão "relações sociais" não compreende, forçosamente, ou apenas, relações de troca. Elas existem tanto numa "economia de guerra", quanto numa comunidade ou em grupos fortemente coesos. Podem, então, designar trocas razoavelmente simétricas ou relações fortemente assimétricas, presentes em expressões como: relações de dominação, relações de conflito, relações de poder, relações de escravidão, relações de agressão, entre outras. Touraine (1986), referindo-se aos conflitos sociais, distingue as noções de integração e de interação. Para ele, as partes em conflito têm relações de interdependência ou de interação, quando pertencem a um mesmo sistema. Assim, só há conflitos entre patrões e operários porque os dois lados fazem parte do mundo do trabalho, de um mesmo sistema político, jurídico e econômico-social. Dahrendorf (1981) observa até que os conflitos pressupõem "uma comunidade” entre as partes em luta. Por isso, diz ele, não há conflitos entre as donas de casa alemãs e os enxadristas peruanos, pois não existe relação alguma entre esses dois grupos. Em síntese: a interação designa também relações fundadas na violência. Citemos, no plano da vida privada, o exemplo de filhos que maltratam e até assassinam os pais ou vice-versa; no plano macrossocial, as guerras civis, as ingerências sangrentas das grandes potências nos países periféricos, a escalada do terrorismo, a violência urbana; no plano econômico, as estratégias desleais de competição entre empresas ou entre nações concorrentes. Vemos aí interações destituídas tanto de integração quanto de troca.

Se este ensaio tem como objeto as relações de troca, julgamos oportuno, para melhor delimitá-las conceitualmente, interrogarmo-nos sobre os modos de relação nos quais as trocas estariam ausentes. Vamos aqui aproveitar uma pista deixada por Perroux (1960) que, ao analisar as "sociedades negociantes” do ocidente europeu, afirma que elas não prosperaram apenas com base nas receitas da economia de mercado, pois seus sistemas de trocas sempre foram atravessados pelas práticas da coação e do dom.

Embora o autor situe as práticas de coação e do dom no interior dos sistemas de trocas - e ele o faz estritamente no terreno da economia de mercado -, vamos nos apropriar destas duas noções, à nossa maneira, situandoas em planos que extrapolam as relações de mercado, para chegar até onde, 
por hipótese, as trocas estão estruturalmente ausentes. Propomos, assim, três cenários que apontam para três formas "relacionais" distintas:

a) as relações de troca propriamente ditas, formais e informais, tomadas como paradigma das relações que traduzem o processo civilizatório, mesmo se admitimos que as trocas só idealmente são simétricas;

b) as relações de coação, que podemos desdobrar em dois planos: no primeiro, estão as trocas que, embora legalmente ratificadas, são estruturalmente perversas e assimétricas, caracterizando um quadro de relações de exploração do semelhante. Aqui poderíamos listar múltiplas faces da exploração do outro, no trabalho, na família, nas relações amorosas etc. No segundo, estão as relações de violência, nas quais as trocas estão totalmente descartadas. Falamos aqui dos conflitos que sucumbiram às negociações, resultando em guerras, terrorismo político e religioso, violência urbana, violências internas aos pequenos grupos, na família, na rua, bem como relações fortuitas entre indivíduos que, por razões diversas, visam a se destruir;

c) as relações caracterizadas pela prática do dom (dádiva, presente), que, à primeira vista, assinala a ausência de trocas, pois remete a um dar unilateral, sem retribuição. Aqui também podemos explorar dois planos: o primeiro se refere às dádivas aparentemente gratuitas, tais como Mauss (1908/1974) pesquisou nas sociedades arcaicas e estendeu às sociedades contemporâneas, mostrando, no entanto, que se referem a formas de troca anteriores à racionalidade do mercado. O segundo se refere às tradições discursivas, de conotação místico-religiosa, que pretendem localizar, nas relações entre Deus e o homem, a essência do gesto gratuito, radicalmente destituído de troca. Discutiremos a tese da gratuidade, questionando sua viabilidade, tanto no plano conceitual quanto no plano empírico do mundo humano.

\section{Hipóteses de trabalho}

Se as relações de troca ocorrem, mesmo que assimetricamente, nos mais diversos níveis das interações humanas, sua abordagem teórica supõe uma multiplicidade de olhares. Foi o "Ensaio sobre a dádiva” (Mauss, 
1908/1974) que nos inspirou neste trabalho. Por meio dele, pudemos avançar em outras leituras. As considerações feitas até aqui permitem que tracemos as seguintes premissas, relativas à abordagem das trocas:

- o fundamento das relações ditas civilizadas entre indivíduos, coletividades e instituições, em qualquer contexto da história e da cultura, nos domínios público e privado, sustentam-se na reciprocidade das prestações de serviços ou na transferência de bens materiais, simbólicos, afetivos e cognitivos, entre outros - a isso chamamos relações de troca;

- as relações de troca seriam, no plano inter-humano, a alternativa à violência pura ou aos conflitos que emanam do desejo de destruição ou anulação do outro. A guerra seria o protótipo da recusa de trocas entre as nações, com suas variantes macro e microssociais, nos campos da política, da economia de mercado, das instituições sociais, das organizações do trabalho, dos grupos familiares, científicos, esportivos, além das relações destrutivas entre indivíduos;

- algumas formas de troca sugerem que uma parte transfere a outra algum bem ou "presente", num gesto aparentemente espontâneo e gratuito. Elas se referem à economia da dádiva (Mauss, 1908/1974), e se caracterizam como uma forma específica de troca, típica das sociedades arcaicas, mas presente também nas sociedades contemporâneas;

- no plano conceitual, as relações desprovidas de trocas se dividem em dois grupos: de um lado, aquelas em que as partes em conflito buscam se eliminar física ou simbolicamente; de outro lado, aquelas marcadas pela ausência radical da reciprocidade, pois uma parte transfere algum bem material ou imaterial à outra, de maneira unilateral ou gratuita;

- as relações de troca, formalmente fundadas na reciprocidade, quase nunca ocorrem segundo um justo equilíbrio de ganhos materiais ou simbólicos, entre as partes em interação. Tomamos, entre muitos exemplos possíveis, as relações de trabalho, regidas pela mais-valia (Marx, 1865/1974), como o paradigma de uma troca jurídica e socialmente legitimada, mas fundada na assimetria entre o dar e o receber: troca-se força de trabalho por 
salários geralmente insuficientes, pelo desgaste físico e mental, pelo adoecimento, pelo assédio moral, por acidentes ou até a morte no trabalho;

- apesar de serem garantidoras do laço social, como alternativa à guerra e outras formas de violência, as relações de troca são fonte permanente de conflitos, mais ou menos graves, implícitos ou explícitos;

- os conflitos inerentes aos processos de trocas apontam para duas alternativas: a) uma negociação bem sucedida, entre as partes, selada por pactos, acordos, contratos etc.; b) rupturas de gravidade variável, cujo limite é a tentativa de eliminação efetiva da parte oponente, seja ela um indivíduo, um grupo, uma instituição ou uma coletividade. Voltamos aqui ao modelo da guerra. A tentativa de eliminar a outra parte pode ser física ou simbólica esta última se caracterizando como eliminação econômica, institucional, racial, étnica, social ou afetiva, entre outras.

Dadas essas premissas, vamos nos interrogar, inicialmente, como numa dúvida metódica, se é possível elegermos algum contexto sócio-histórico caracterizado pela ausência - real ou aparente - das relações de troca. Apontamos acima dois cenários fundados nesta ausência: o primeiro tem a guerra como paradigma, desembocando nas múltiplas tentativas de eliminação material, simbólica ou institucional da parte oponente. No entanto, podemos ir além das situações empíricas que explicitam a "guerra”, recorrendo a um "momento conceitual” que, apesar de não resgatável historicamente, pode ser essencial para nos ajudar a compreender os fundamentos das relações sociais regidas ou não pela instituição da troca. Trata-se, com efeito, de dois momentos míticos. Um deles é extraído por Freud da antropologia, remetendo à horda primitiva comandada por um pai tirano; o segundo, evocado por Hobbes, também se refere a um momento anterior ao nascimento da cultura, ou seja, o "estado de natureza”, fundado na hipótese de uma "guerra de todos contra todos”, pois nele o homem não passaria de um lobo do homem.

Um outro cenário, situado para além da economia da dádiva (Mauss, 1908/1974) e, às vezes, decantado como modelo de comportamento, referese à idéia do gesto radicalmente gratuito e altruísta. Trata-se de uma outra economia, isto é, a economia da graça, fundada nos discursos religiosos, 
especialmente na tradição neo-testamentária do cristianismo, e que tem como foco as relações entre Deus e o homem. Vamos nos ocupar, em seguida, destes dois contextos, que seriam, segundo as hipóteses aqui desenvolvidas, contextos míticos.

\section{O primeiro mito de um mundo sem trocas}

Seria possível pensarmos, abstratamente, um quadro social qualquer, no qual as interações entre humanos fossem estruturalmente desprovidas de qualquer comércio? Talvez seja possível respondermos que sim, se tal quadro for apenas conceitual, abstrato, um mito ou ficção teórica, pois ele seria impensável no conjunto da cultura humana, se localizarmos o nascimento da cultura justamente na emergência das formas primitivas de troca.

Antes de evocar essas ficções teóricas, em Hobbes e em Freud, vamos nos deter, de passagem, na especulação relativa a um mundo puramente natural, que Bergeret (1984) descreve como regido por uma "violência fundamental”. O autor define essa violência como uma energia primitiva de base, que fornece a cada indivíduo os elementos essenciais para a sua natural "luta pela vida". Uma das marcas dessa violência natural é a indiferença, a ausência de sensibilidade ao sofrimento do outro (tomemos o caso do animal que devora outro, um não-semelhante, para se alimentar). Nessa indiferença não haveria nem amor nem ódio, nem cobiça ou inveja. Ela não se identifica, pois, com as noções de crueldade, maldade ou perversão, só atribuíveis ao animal humano, ou seja, regidas por uma intencionalidade. A "violência fundamental”, em Bergeret (1984), pode então ser assimilada à noção de agressividade natural, instintiva, diferente da violência que marca o mundo humano. Mas qual é a lei que rege esse mundo natural? Bergeret lembra que a luta primitiva pela vida vai desembocar na máxima "ou ele ou eu”. Daí a impossibilidade de sobreviver a dois. Ou a impossibilidade cabal de alguma negociação, de alguma renúncia, de pactos ou partilhas, vistas como bases das relações de troca, das relações culturais. 
Vamos repetir que esse cenário é típico do mundo da natureza, ou seja, anterior ao nascimento da cultura, na qual se instituem as trocas. No entanto, sabemos que, se a máxima "ou ele ou eu” remete primordialmente à luta biológica pela vida, ela se perpetua em diversas modalidades ou momentos da interação entre humanos, ao longo da História. Em outras palavras, a "ou ele ou eu” invade os pactos que selam o laço social, marcando a dualidade insuperável entre as forças da civilização e da barbárie.

Tomemos, então, as ficções teóricas que remontam ao momento de passagem entre uma "violência primitiva", que situa o homem em seu estado natural, e o nascimento da civilização ou das sociedades. Trata-se, com efeito, de conhecidos "conceitos operatórios" de trabalho, de duas "lendas" antropológicas que tentam remontar às raízes do processo civilizatório. A primeira delas, formulada por Hobbes (1651/1979), no Leviatã, diz respeito ao estado de natureza, palco da guerra de todos contra todos, no qual cada homem é comparado a um lobo diante de cada outro homem. A segunda se refere ao tempo das "hordas primitivas", análogo ao estado de natureza hobbesiano, cenário privilegiado para Freud reconstruir, à luz da psicanálise, a história de um pai tirano, um macho poderoso que tomava para si todas as fêmeas da horda, privando os filhos das suas satisfações libidinais ou da posse das fêmeas.

Examinemos brevemente esses dois momentos, apontando os aspectos que interessam ao fio condutor de nosso trabalho. É importante observar, como nos lembra Dor (1991, pp. 22-23), que o estado de natureza, em Hobbes, bem como a horda primeva à qual Freud se refere, em Totem e Tabu, são hipóteses não recuperáveis historicamente. Este autor acrescenta que, para Rousseau, a ficção do estado de natureza hobbesiano é uma exigência da razão ou um conceito operatório necessário, pois ele sustenta concepções coerentes sobre a constituição das sociedades. Além disso, quando Hobbes evoca um “estado de natureza”, ele não se refere à pré-história da humanidade, mas a toda situação, antiga ou atual, que remete à falta de um princípio político capaz de garantir a ordem social. 
Na obra De Cive (Sobre o Cidadão), Hobbes já afirma com vigor a idéia de egoísmo, traduzida na conhecida expressão homo homini lupus. Ele diz, por exemplo:

Mas a causa mais comum que leva os homens ao desejo de se ofender e se prejudicar uns aos outros é que muitos deles buscam ao mesmo tempo uma mesma coisa. Acontece muito freqüentemente que eles não podem possuir tal coisa em comum e que ela não pode ser dividida. (Hobbes, 1642/1982, p. 96)

Nesse caso, cada homem tem o direito (entenda-se: direito de nature$z a$, desligado da cultura, que não leva em conta o outro) de empregar todos os meios sem os quais não chegaria aonde deseja. É neste mesmo texto que o autor afirma que o “...estado natural dos homens, antes que eles tivessem formado as sociedades, era uma perpétua guerra, e não só isso, mas uma guerra de todos contra todos." (Hobbes, 1642/1982, p. 99).

Ao trabalhar o conceito de desejo, fundamental em sua análise da alma humana, o filósofo parece afirmar que o objeto de desejo, por excelência, é o poder. Sobre isso, ele escreve: “Assinalo assim, em primeiro lugar, como tendência geral de todos os homens, um perpétuo e irrequieto desejo de poder e mais poder que cessa apenas com a morte” (Hobbes, 1651/1979, p. 60).

Para o filósofo, tal quadro descarta a idéia natural de altruísmo, uma vez que natural seria o egoísmo, essa inclinação geral do gênero humano. Para se passar desse cenário ao estado de cultura foi necessário um pacto digamos: um sistema global de trocas - concretizado na escolha de um soberano que governasse a todos. Embora esse soberano tivesse a aura do absolutismo (ou do monstro bíblico Leviatã), ele representava o ingresso dos homens na ordem jurídica, na lei. Nesse caso, o outro não era mais um concorrente a destruir, mas um semelhante com o qual cada indivíduo deveria partilhar o novo regime, partilhar direitos e deveres, o que possibilitava, mesmo que de modo instável, a emergência de um laço social. Em resumo: o egoísmo natural daria lugar à entrada na cultura. Dentro dos propósitos do presente texto, quando falamos de partilha, estamos justamente nos referindo à passagem do egoísmo incondicional do homem lobo (natureza) a um sistema social de trocas entre semelhantes (cultura). 
Passemos a Freud e à horda primeva de filhos e filhas, oprimidos em bloco pelo pai tirano. Nessa horda, a transição de um estágio primitivo bárbaro à civilização ocorreu, não por meio de um pacto, mas de um complô dos filhos que assassinaram esse pai e o devoraram, num banquete antropofágico. Freud escreve:

Certo dia, os irmãos que tinham sido expulsos retornaram juntos, mataram e devoraram o pai, colocando assim um fim à horda patriarcal. Unidos, tiveram a coragem de fazê-lo e foram bem sucedidos no que lhes teria sido impossível fazer individualmente. (Algum avanço cultural, talvez o domínio de uma nova arma, proporcionou-lhes um senso de força superior). Selvagens canibais como eram, não apenas matavam, mas também devoravam a vítima. (Freud, 1913/1974, p. 170)

Se Hobbes vê o poder como objeto privilegiado do desejo, Freud associa o desejo tanto ao poder quanto à sexualidade: "Odiavam o pai, que representava um obstáculo tão formidável ao seu anseio de poder e aos desejos sexuais...” (Freud, 1913/1974, p. 171).

O assassinato e a ingestão do pai tirano gerou também, na interpretação de Freud, o arrependimento dos filhos e a identificação com esse pai. Mas essa mudança de bárbaros assassinos e canibais em irmãos arrependidos, ou seja, irmãos entronizados na cultura, já não tinha como objeto o pai vivo, em sua face tirana, mas o pai depois de morto, recriado então como totem, venerado e divinizado:

...mas amavam-no também. Após terem-se livrado dele, satisfeito o ódio e posto em prática os desejos de identificarem-se com ele, a afeição, que todo esse tempo tinha sido recalcada, estava fadada a fazer-se sentir e assim o fez sob a forma de remorso. Um sentimento de culpa surgiu, o qual, nesse caso, coincidia com o remorso sentido por todo o grupo. O pai tornou-se mais forte do que o fora vivo. (Freud, 1913/1974, p. 171).

O pai totemizado passa a ser a referência mítica da fundação e da sustentação da nova sociedade dos filhos, que assim inauguram o processo da civilização. E celebram entre si um pacto baseado na interdição dos crimes que tanto o pai quanto eles, os filhos, haviam cometido anteriormente: o 
incesto, o assassinato e o canibalismo, crimes esses que os antropólogos consideram as interdições fundamentais a toda cultura.

Segundo nossa hipótese de trabalho, tanto no estado de natureza quanto na horda primitiva estava descartada qualquer possibilidade de troca ou reciprocidade entre os indivíduos. Cada qual via o outro como um obstáculo, um concorrente a destruir. Estes dois cenários pré-civilizados tinham em comum a ausência de leis ou de interdições ou, se quisermos, eram regidos pela violência pura. O mito hobbesiano fala, aliás, de uma igualdade entre todos os homens, mas uma igualdade de natureza: todos eram iguais no egoísmo, no desejo de poder e mais poder, de se destruir mutuamente, na força física e nas qualidades intelectuais, donde a guerra entre todos esses "iguais".

Por sua vez, se a lenda do pai tirano sugere uma desigualdade, esta seria apenas aparente: o tirano era um só, a dominar os filhos e as fêmeas da horda. Tratar-se-ia aqui de uma "guerra do um contra todos", em vez de "todos contra todos". Ora, sabemos que os filhos, pelo menos até o momento do complô, não tinham qualquer organização social. Ou qualquer sistema de trocas. Se internamente entre eles não havia uma guerra generalizada, nada havia também em comum, nem um pacto nem um projeto de sociedade. Eram algo que Sartre (1960) chamaria de aglomerado ou série, ou seja, uma dispersão de solitários selvagens, submetendo-se como horda à opressão do poderoso pai. No entanto, o fato de se unirem, para assassinar e devorar o pai, já prenuncia um fato social, isto é, a formação de um grupo, com um projeto comum. Note-se que este projeto tem ainda um conteúdo bárbaro, pois os filhos se mostram "iguais ao pai”, em força e em violência. Sobre isso, aliás, Hobbes (1651/1979, p. 74) comenta como o mais fraco pode se igualar ao mais forte: "o mais fraco tem força suficiente para matar o mais forte, quer por secreta maquinação, quer aliando-se com outros que se encontrem ameaçados pelo mesmo perigo". É isso que ocorre, quando os irmãos da horda se unem para assassinar o pai. Freud evoca até um rudimento de cultura, ou seja, o domínio de alguma nova arma, que deu aos filhos o senso de força superior. Em resumo, os filhos, ao se unirem, se tornaram "iguais" ao pai, iguais em força. 
Relações Sociais: as Trocas e os Mitos de um Mundo sem Trocas

\section{As trocas nascem com o pacto}

Nos dois casos - estado de natureza ou horda primitiva - estamos diante de um mundo no qual nada se pactuou, no qual nenhuma relação de troca tinha lugar. É através dessa idéia genérica de pacto (ou contrato social) que podemos problematizar o tema da troca. Em outras palavras, o pacto social seria o paradigma, o fundamento da idéia de troca, a possibilidade de nascimento das sociedades, do processo civilizatório.

Quais seriam então os argumentos que nos permitem abordar a instituição da troca? Tomemos, de início, pelo menos um: a troca supõe a passagem de um estado primitivo violento a um estado de civilização. Digamos, apoiados em Freud, que esse momento pode ser definido como a partilha inaugural da renúncia:

...é impossível desprezar o ponto até o qual a civilização é construída sobre uma
renúncia ao instinto, o quanto ela pressupõe exatamente a não-satisfação (pela
opressão, repressão, ou algum outro meio?) de instintos poderosos. Essa
"frustração cultural” domina o grande campo dos relacionamentos sociais entre os
seres humanos. (Freud, 1913/1974, p. 118)

Freud acrescenta que, na renúncia contida no pacto, os filhos “anularam o próprio ato, proibindo a morte do totem, o substituto do pai; e renunciaram aos seus frutos, abrindo mão da reivindicação às mulheres que agora tinham sido liberadas” (Freud, 1913/1974, p. 118).

Observemos que desses textos de Hobbes e de Freud decorre um outro princípio óbvio, mas que recolocamos aqui, em função de nossa linha argumentativa: se o regime de trocas nasce com a experiência da renúncia, ele se ancora também na "descoberta" da alteridade. Falemos de descoberta não apenas no sentido de algo novo que se abre aos olhos do grupo - da nova sociedade -, mas de um desdobramento inerente à mudança operada nas relações afetivas e políticas entre seus membros. Com efeito, no estado de natureza e na horda primitiva, cada indivíduo era apenas um obstáculo a evitar e a destruir. Ele não era um alter, no sentido de quem tem (ou é) algo de mim mesmo, um semelhante. A sensibilidade ao desejo e ao sofrimento 
do outro só ocorre se o "descobrimos” como alter ego, outro eu, como tela de projeção e identificação do que desejamos, fazemos, sentimos. O que se passa com o outro pode se passar também comigo. Enfim, no estado de natureza, o outro não era um socius, não havia lugar para a partilha, para a reciprocidade. O estado de cultura inaugura o tema hegeliano da identidade e da diferença: "só podemos falar de um Outro que é minha diferença absoluta se ele for ao mesmo tempo idêntico a mim (...) se ele é em-si e para-si igual a mim, será preciso avançar na direção de uma identidade construída mediante o reconhecimento recíproco” (Santos, 1993, p. 20).

\section{O segundo mito de um mundo sem trocas}

O segundo momento, como dissemos, se localiza no reino da gratuidade. Diferentemente das ficções anteriores, situadas num estágio bárbaro da humanidade, representado como inferior, a idéia de gratuidade seria associada a um estágio supostamente superior do processo de civilização, situado no pólo oposto àquele de nossos impulsos egoístas. Aqui, o mal-estar humano dá um salto no sentido contrário das inclinações possessivas, rumo à renúncia total de si, em favor do outro. O fundamento histórico desse modo de interação data do Novo Testamento e vem de um gesto não-humano, ou seja, divino: Cristo dá a vida pela humanidade. Ele ocorre num momento histórico no qual, segundo Tarot (1993), as questões religiosas e políticas mais uma vez se davam as mãos: para o povo judeu, era crucial reinterpretar a herança divina, a fim de assegurar sua sobrevivência cultural e política, num mundo em transição. A "nova mensagem” de Jesus emerge em torno do dom gratuito (donum gratis datum), ou seja, em torno da economia da graça. Ela se distingue das demais concepções da época, baseadas, por exemplo, na máxima "olho por olho, dente por dente”. Bergeret (1984) lembra, neste sentido, que as antigas representações das divindades conferiam a elas a posse e o uso da violência. Assim, no Deuteronômio, Deus diz que "a vingança me pertence”. 
Não vamos nos deter aqui na problemática teológica que envolveu seculares polêmicas, de Agostinho a Lutero, incluindo o aspecto terrificante da predestinação, ou seja, da imprevisibilidade de Deus, que concedia a cada indivíduo a graça da salvação ou a desgraça da condenação. Alberoni (1990) mostra que a versão agostiniano-luterana dessa economia postula a radicalidade da graça (da salvação): não é necessária a cooperação ou a ação do homem, para obtê-la. O desconhecido da predestinação (estou previamente salvo ou condenado?) seria uma fonte permanente de angústia existencialreligiosa, além de apontar para uma inexplicável “injustiça” divina, pois, em seus “insondáveis desígnios”, Deus concede ou nega, imotivadamente, a graça. Alberoni lembra que, contra Agostinho, Pelágio postulava que o homem deve colaborar com Deus para ganhar a salvação. A própria Igreja adotaria, mais tarde, uma linha semi-pelagiana, uma posição intermediária entre o dom incondicional de Deus e a ação meritória do homem para se salvar. Esta posição permaneceu ambígua, pois defendia, a um só tempo, a graça incondicional (Deus nada exige de troca) e a prática do sacrifício, das boas ações, da renúncia aos desejos "mundanos”, como moeda de troca para o homem se salvar.

Polêmicas à parte, interessa-nos aqui sublinhar a emergência de um discurso que se notabiliza pela novidade sedutora do dom altruísta, imotivado, gratuito. Mas seria ele humanamente pensável ou politicamente desejável? Quais as consequiências da eliminação radical da troca, fundamento do laço entre os homens? Em que lugar estariam os dois atores, quando, numa relação estruturalmente assimétrica, um só dá e o outro só recebe? Não seria a idéia da gratuidade atribuída apenas a Deus, jamais ao homem? Com efeito, só um ser onipotente poderia render-se a uma relação sem trocas, já que ele de nada carece. Por outro lado, uma abordagem antropológica (pois não são as questões teológicas ou de crença que estão aqui em jogo) pode se interrogar sobre o dom divino, ou seja, será que Deus se interessa mesmo por essa economia da graça? Esta questão é posta por Anders Nygren (citado por Alberoni, 1990), para quem os deuses não amam, vivem suas vidas felizes, sem se perturbarem pelo desejo ou pela necessidade. $\mathrm{O}$ amor vem de baixo, é matéria humana. Alberoni, neste mesmo texto, lembra ainda Aristó- 
teles, para quem todas as coisas tendem para Deus, mas Deus não tende para nada, não faz nada. Ele é o motor imóvel: Deus sublunaria non curat (Deus não se ocupa das coisas abaixo da lua).

E da parte do homem? Se ele é finito, ser de carência, como pode postular o jogo da gratuidade, jogo que remete a uma desigualdade estrutural? Com efeito, uma parte só dá, de forma absolutamente desinteressada ou imotivada, sem nenhuma contrapartida, enquanto a outra, que só recebe, não só está desobrigada da retribuição, mas, pior ainda, não tem como retribuir, pois ao doador nada falta. Em síntese: essa “interação” anula a possibilidade das trocas, da reciprocidade. Assim, só podemos concluir pela impossibilidade lógica e antropológica da gratuidade, pois “dar de graça” só se aplica aos deuses. A troca é o que resta ao homem, este ser marcado pela falta.

O gesto radical de gratuidade seria, no plano humano, conceitualmente impensável e eticamente suspeito: o sujeito do dom gratuito dá a entender que nada lhe falta. E coloca o recebedor no lugar da pura impotência, pois nada pode retribuir, herdando uma dívida eterna e impagável. Tal desigualdade anula a alteridade, ou seja, aquilo que dá ao outro o lugar de semelhante, de socius.

A esta altura, importa sublinhar a distinção fundamental entre o dom supostamente gratuito ou desinteressado e o dom que traz algum retorno ao doador - e todo retorno é ganho, é "renda", é "lucro", sejam eles apenas simbólicos. Mesmo que o dom carregue as marcas efetivas da generosidade, da solidariedade, do amor ou da amizade, ele não comporta a idéia de gratuidade. Trata-se aqui de um princípio evidente por si mesmo: todo gesto de solidariedade, toda dádiva, por mais que seja altruísta, caso não renda ao doador um ganho mercantilista, rende-lhe certamente um quantum de satisfação pessoal, íntima, narcísica, além de reconhecimento social, poder ou status. Imaginemos os ganhos íntimos, o reconhecimento social e poder de influência - o exemplo é paradigmático - de uma Madre Teresa de Calcutá. Assim, o dom seria também uma forma implícita de troca. Entendemos, pois, que os vínculos inter-humanos são efetivamente permeados pelo dom, mas que este 
não é sinônimo de ato gratuito. Em síntese, a gratuidade não é affaire do animal humano.

O ensaio de Mauss (1908/1985) sobre a economia da dádiva chega à evidência fundamental, assinalada, aliás, no subtítulo de sua obra, de que o dom (ou dádiva) é “forma e razão de troca”, e sua prática é comum às sociedades arcaicas e contemporâneas. Daí sua afirmação de que a dádiva, o presente, estão ligados a interesses e ganhos, num complexo sistema de trocas baseado no tripé essencial: “dar, receber, retribuir”. Além de mostrar como os primitivos trocam com a divindade, a fim de prevenir desgraças, ele analisa a esmola (dar sem retribuição) como uma forma de perpetuar a dominação do mais forte sobre o mais fraco.

A esta altura, a discussão em torno do dom gratuito nos remete a duas perguntas: de um lado, como pôde o discurso da gratuidade impregnar tão profundamente a cultura ocidental?; de outro, não seria ele uma fonte de equívocos ou, mais ainda, um instrumento ideológico que serve a práticas perversas de sedução e de perpetuação de sistemas ou de relações de dominação? Não vamos aqui nos debruçar sobre estas perguntas, pois apenas lembramos a complexidade que elas evocam. O que tentamos, neste ensaio, é demonstrar que os dois cenários míticos - o primeiro, do homem lobo ou da horda primitiva; o segundo, do reino da gratuidade - apontam para a ausência estrutural das trocas entre indivíduos, grupos, instituições ou coletividades quaisquer.

Recapitulando: num mundo sem trocas, pré-cultural ou supra-cultural, teríamos duas alternativas de interações. Com as lendas de Hobbes e Freud, resta o regime da pura violência, o uso bárbaro da força e do poder, o impulso único de eliminar o outro, no estilo “ou ele ou eu”. Com a tradição neo-testamentária, resta a desigualdade estrutural entre, de um lado, o portador do dom imotivado e gratuito e, de outro lado, aquele que recebe sem possibilidade de retribuir. Nos dois casos, fica descartada a instituição social da troca.

Além de um ponto fundamental em comum, ou seja, a ausência da troca, haveria outras aproximações entre esses dois cenários? Vejamos: no 
estado de natureza, a noção de igualdade diz respeito a uma igualdade natural, ou seja, a mesma capacidade que todo indivíduo tem de destruir qualquer outro. Já no reino da gratuidade, essa potência destrutiva é unilateral: aquele que só dá ocupa um lugar desigual, superior, em relação a quem só recebe. Outra observação: essa ausência de trocas ocorre ora num tempo pré-histórico (estado de natureza), ora num tempo pós-histórico (a graça divina, afinal, é a “salvação”). Resta-nos então constatar: o tempo histórico, tempo do processo civilizatório, é o tempo das trocas, porque o homem é um ser de escassez material ou de escassez interiorizada. Da escassez material nasceu, por exemplo, a divisão social do trabalho, da qual Durkheim (1893/1991) extraiu a noção de solidariedade orgânica, que reside essencialmente na necessidade e na conseqüente instituição das trocas. Da escassez interiorizada (Sartre, 1960) nasceram todas as formas de sociabilidade que marcam a cultura humana, como espaço de interação e trocas, mesmo que estas comportem a desigualdade entre o dado e o recebido. No entanto, foi a escassez material e psíquica - fonte permanente de angústia - que fez nascer a técnica, a religião, a ciência, a arte, o esporte etc. Tais criações culturais apontam para a solidariedade - este é um outro nome para a troca - entre os seres inacabados, solidariedade esta que se descola tanto da violência précivilizatória quanto da gratuidade típica de um “outro mundo”.

\section{Por que as trocas são fonte de conflitos?}

Até aqui, ao evocar esses momentos míticos de um mundo sem trocas, nosso propósito não foi outro senão introduzir argumentos para a hipótese de que não há civilização sem pactos e que o pacto representa, em termos culturais, políticos, jurídicos e psíquicos, a institucionalização de sistemas de trocas. É evidente que tais sistemas obrigam a renúncias e supõem ganhos, nos planos individual e coletivo. Nessa ótica, em vez de "definir" o animal humano segundo concepções clássicas ou contemporâneas - tais como: animal racional, animal louco, animal simbólico, paixão inútil, ser de desejo, ser-para-a-morte, homo sapiens-demens etc. -, apoiamo-nos em Aristóteles 
que o chamou de animal político, conotação esta que, no presente caso, renomeamos como animal de trocas. Mas o filósofo diz que esse animal é naturalmente político e nisso ele é criticado por Hobbes, pois natural seria o homem lobo do homem. De fato, é o estado de cultura que faz de nós um animal de trocas. Neste sentido, vamos conservar a distinção entre natureza e cultura, tendo em conta que a chamada "natureza humana” só é humana porque marcada por uma atividade cultural (o trabalho, no sentido hegeliano e marxiano) que a distingue e a leva além da atividade "natural” ou puramente instintiva do animal.

Segundo nossa hipótese, as trocas têm lugar: a) porque o homem não é um animal apenas egoísta e agressivo, à maneira do lobo hobbesiano ou o pai tirano da horda primitiva. Seu medo da morte fez dele também um animal social, solidário, de "com-paixão" ou "sim-pático": em grego, o syn (com, junto de, ao mesmo tempo) e o pathos (aquilo que, bem ou mal, afeta o corpo e a alma) (Bailly, 1991, p. 642) indicam a condição de co-sentir, cosofrer ou, no limite, co-identificar-se no sofrimento, na alegria, na percepção da própria finitude ou, até mesmo, nas veredas imaginárias da ilusão, da onipotência, da perversão; b) porque a troca não é a encarnação "sublime” do puro altruísmo, traduzido como gratuidade, nem da pura violência que visa a anular o outro. O homem lobo, tanto quanto o sujeito da gratuidade, se esquivam à possibilidade de "ser-com", de "sentir com", de tratar o outro como semelhante. Ao contrário, dirigem-se ao outro como um diferente, estranho, inferior, fazendo dele ora um inimigo a destruir, ora um devedor de uma dívida impagável. Nos dois casos, o outro é eliminado ou negado como socius.

Mas sabemos que, nos planos macro e microssocial, o processo civilizatório não é um estágio definitivo que tenha superado o estado de natureza, nos moldes de uma "sociedade reconciliada", do "absoluto da cultura”, do "fim da História”, caros às utopias hegeliana ou marxiana, embora com horizontes distintos, para os dois filósofos. Mais problemático ainda seria cindir a espécie humana entre "apenas doadores" e "apenas recebedores”, o que remeteria, nesse caso, ao fim das sociedades de trocas. 
Se o pacto social implica a superação do estado natural bruto, tanto Hobbes quanto Freud não deixaram de vislumbrar nele um "mal-estar” estrutural. Para o filósofo, cada indivíduo renuncia ao seu direito à liberdade individual, da qual era possuidor no estado de natureza, substituindo-a pela segurança garantida pelo estado de sociedade, mesmo em se tratando do Estado leviatânico, que reserva a si a violência sobre seus cidadãos. Em outras palavras, ao mesmo tempo em que dá lugar à alteridade, o pacto assinala a entrada na negatividade: cada indivíduo tem de abrir mão de seu anterior desejo de absoluto. No pacto se reparte o negativo ou, se quisermos, inaugura-se a linguagem, a instituição por excelência da troca humana, que dá caminho às demais trocas e reciprocidades, ou seja, a partilha dos códigos ou signos, dos bens, do prazer, das angústias e gozos, dos projetos em comum, relativos às instituições, à sociedade, aos grupos e sub-grupos. Hobbes vê a linguagem como "a mais nobre e útil de todas as invenções (...) pelas quais os homens registram seus pensamentos (...) usam entre si para a utilidade e conversa recíprocas, sem o que não haveria entre os homens nem Estado, nem sociedade, nem contrato, nem paz” (Hobbes, 1651/1979, p. 20).

Apoiados em Freud (1913/1974), diremos que o "mal-estar da cultura” decorre da obrigação que tem cada indivíduo de submeter-se à troca, no cenário da alteridade e da diferença, do encontro permanente com o desejo que não é o seu. Afinal, as trocas não se fundam na pura racionalidade, na harmonia entre indivíduos e coletividades, mas geralmente num contexto explícito ou implícito de conflitos. Estes, por seu lado, não significam, por si mesmos, um obstáculo ao processo civilizador. Ao contrário, são eles que fazem caminhar as sociedades e a História.

Qual seria, então, o lugar e o papel do conflito, no jogo político, econômico e psicossocial que envolve as relações de troca? Muitas teorias podem responder a esta pergunta. Comecemos lembrando a dialética hegeliana do senhor e do escravo, que se define pela "desigualdade das consciências" (Hegel, 1807/1992); ou a abordagem sartreana das trocas, que vê o homem como um "ser de escassez" (Sartre, 1960), mas uma escassez interiorizada e não apenas material. Nesse caso, toda troca colocaria frente a frente um "ser de escassez" com outro "ser de escassez", cada qual constituindo uma ame- 
aça para o outro. Sartre vê na "luta contra a escassez" a fonte da História, que acaba, muitas vezes, desembocando na violência.

Nessa mesma direção se alinham as teses freudianas que poderiam se perfilar em dois eixos: em primeiro lugar, as pulsões de auto-conservação (Selbsterhaltungstriebe) que poderíamos incorporar à idéia de "violência fundamental”, tal como formulada por Bergeret (1984), ou seja, aquela violência que se confunde com uma energia primitiva indiferenciada, que fornece a cada indivíduo os recursos de sua "luta pela vida", no regime do "ou ele ou eu”, máxima esta que, apesar de "primitiva”, ainda permanece nas interações entre indivíduos e instituições, uma vez que ela está presente em nossa dinâmica pulsional. Em outras palavras, toda troca estaria perpassada por essa vertente biológica da luta pela vida, desdobrada em suas vertentes pulsionais e simbólicas. No mesmo plano estariam as pulsões do eu (Ichtriebe), também assimiladas às pulsões de auto-conservação e que, na primeira teoria freudiana das pulsões, apontam para "uma energia colocada a serviço do eu, no conflito defensivo” (Laplanche \& Pontalis, 1988, p. 380); enfim, em toda troca pode ocorrer o concurso das pulsões agressivas (Aggressionstrieb), vistas como a volta para o exterior da pulsão de morte (Todestrieb), juntamente com a pulsão de dominação (Bemächtgungstrieb), “cujo objetivo é o de dominar o objeto pela força” (Laplanche \& Pontalis, 1988, p. 364).

Poderíamos recorrer, quase à exaustão, a outros olhares teóricos ou estéticos sobre o ser humano (a mitologia, a literatura, as artes plásticas, o cinema etc.), que, mesmo sem abordar diretamente o tema, deixam entrever, na instituição da troca, as marcas do conflito, da desigualdade e, muitas vezes, da violência. Assim, tomamos as relações de troca não apenas como uma fonte de consolidação da partilha e da harmonia entre os indivíduos e instituições, mas como uma fonte permanente de conflitos. Nosso trabalho se orienta, pois, na hipótese geral de que as trocas, ao mesmo tempo em que sustentam o processo civilizatório, são permanentemente ameaçadas pelo retorno ao estado de horda. Freud lembrava que, mesmo após os filhos assassinarem o pai e fundarem a nova sociedade dos irmãos, o risco da "guerra fratricida" jazia sob seu novo pacto de não cometer os interditos básicos que, como já dito acima, fundam toda cultura: o incesto, o assassinato e o canibalismo. 
Tal hipótese, evidentemente, não sugere que todo conflito leve necessariamente à violência ou à desagregação do tecido social. Ele tem um custo para as partes que se afrontam, com interesses antagônicos, custo esse que pode desembocar tanto na violência quanto no esforço comum da negociação. Ademais, é importante considerarmos o conflito como um elemento estruturante e necessário às relações inter-humanas. Tanto a Psicanálise como as diversas teorias políticas e sociológicas o consideram como inerente às relações sociais. Se, para a Psicanálise, ele funda a dinâmica da realidade psíquica, sendo uma noção central da teoria das neuroses, para alguns sociólogos, ele é um elemento estruturante da dinâmica social. Segundo Dahrendorf (1981), por exemplo, no conflito se esconde o germe criativo de toda a sociedade e a possibilidade da liberdade. Touraine (1986) sublinha a importância das tensões, dos desequilíbrios, dos contrastes entre os diversos níveis da realidade social, sem os quais seria impossível se pensar em mudanças. Estas foram, por exemplo, as hipóteses básicas de trabalho nas quais nos apoiamos (Araújo \& Carreteiro, 2002), num texto que abordava a psicossociologia dos conflitos.

Terminamos este texto, servindo-nos da noção kantiana de discórdia, que interpretamos como a necessidade social e cultural dos conflitos. Com efeito, o filósofo de Könisberg assim escreveu:

Sem essas qualidades de insociabilidade, pouco simpáticas em si mesmas, fonte da resistência que cada qual deve necessariamente encontrar, face às suas pretensões egoístas, todos os talentos permaneceriam para sempre ocultos em germe, no meio de uma existência de pastores de Arcadia, em uma concórdia, uma satisfação e um amor mútuos perfeitos. Os homens, doces como as ovelhas que eles fazem pastar, praticamente não dariam à sua existência mais valor que aquele dado aos seus animais; eles não preencheriam o nada da criação (...) Agradeçamos à natureza por este humor pouco conciliante, pela vaidade que rivaliza com a inveja, pelo apetite insaciável de posse ou mesmo de dominação. Sem isso, todas as excelentes disposições naturais da humanidade seriam sufocadas por um eterno sonho. O homem quer a concórdia, mas a natureza sabe melhor que ele aquilo que é bom para a sua espécie: ela quer a discórdia. (Kant, 1784/1947, p. 64)

Apoiados neste filósofo, digamos que a ausência de conflitos conduziria à paralisação da dinâmica social, da angústia criadora, da invenção de 
novas formas de sociabilidade, enfim, conduziria à entropia tanto da realidade social quanto da realidade psíquica. Numa palavra: sem conflitos, provavelmente, não haveria o tempero criador que anima e dinamiza essa fundamental tarefa cultural chamada troca.

Araújo, J. N. G. (2006). Social Relationships: Exchanges and Mythes in a world without exchanges. Psicologia USP, 17 (1), 155-179.

\begin{abstract}
This essay discusses the phenomenon of the exchange, taken as the institution that founds both cultural and social relationships. The search for comprehending this phenomenon is based on the analysis of two mythical-theoretical moments in which the interaction forms are marked by the absence of the exchange: on one hand, the operational concepts related to a pre-cultural stage of mankind, mentioned in different moments by Hobbes and by Freud, in a context of pure violence; on the other hand, the invention of the idea of gratuitousness that supposes the impossibility of reciprocity, due to the unequal structure between the parts in interaction. Although we take the exchanges as the major foundation of social relationships, typical of the advanced stages of culture, we sustain also that, most frequently, they are traversed by inequality and constantly by the irruption of conflicts. Those are nevertheless considered as an essential element for the cultural development and for the dynamics of social relationships.
\end{abstract}

Index terms: Social interaction. Violence. Conflict.

Araújo, J. N. G. (2006). Rapports Sociaux: Échanges and Mythes dans a monde sans échanges. Psicologia USP, 17 (1), 155-179.

Résumé: Cet essai discute le phénomène de l'échange, vu comme l'institution fondante de la culture et des rapports sociaux. La quête de compréhension de ce phénomène s'appuie sur l'analyse de deux moments mythico-théoriques dans lesquels les modes d'interaction sont marqués par l'absence d'échanges: d'une part, les concepts opératoires relatifs à un stage pré-culturel de l'humanité, evoqués différemment par Hobbes et par Freud, dans un contexte de pure violence; d'autre part, l'invention de l'idée de 
gratuité, ce qui suppose l'impossibilité de la réciprocité, vu l'inégalité structurelle entre les parties en interaction. Même si on considère les échanges comme le fondement majeur des rapports sociaux, typique des stages avancés de culture, cela n'empêche pas que, pour la plupart, ils sont également traversés par l'inégalité et marqués en permanence par l'irruption de conflits. Néanmoins, ceux-ci sont considérés comme un élément essentiel pour le développement de la culture et la dynamique des rapports sociaux.

Mots-clés: Rapports d'échange. Violence. Conflit.

\section{Referências}

Alberoni, F. (1990). Altruísmo e moral. Rio de Janeiro: Rocco.

Araújo, J. N. G., \& Carreteiro. T. C. (2002). Conflit. In J. Barus-Michel, E. Enriquez, \& A. Lévy, Vocabulaire de psychosociologie - reférences et positions (pp. 94-107). Ramonville Saint-Agne, France: Éditions Erès.

Bailly, A. (1991). Abrégé du dictionnaire Grec Français. Paris: Hachette.

Bergeret, J. (1984). La violence fondamentale. Paris: Dunot.

Dahrendorf, R. (1981). Sociedade e liberdade. Brasília, DF: Editora Universidade de Brasília.

Dor, J. (1991). O Pai e sua função em psicanálise. Rio de Janeiro: Zahar.

Durkheim, E. (1991). A divisão do trabalho social. Lisboa: Presença (Trabalho original publicado em 1893).

Freud, S. (1974). Totem e Tabu. In S. Freud, Edição standard brasileira das obras psicológicas completas de Sigmund Freud (Vol. 13). Rio de Janeiro: Imago. (Trabalho original publicado em 1913)

Hegel, G. W. F. (1992). Fenomenologia do espírito. Petrópolis, RJ: Vozes. (Trabalho original publicado em 1807)

Hobbes, T. (1979). Leviatã, ou matéria, forma e poder de um estado eclesiástico e civil (2a ed., Col. Os Pensadores). São Paulo: Abril Cultural. (Trabalho original publicado em 1651)

Hobbes, T. (1982). Le Citoyen ou les fondements de la politique. Paris: GF-Flammarion. (Trabalho original publicado em 1642) 
Relações Sociais: as Trocas e os Mitos de um Mundo sem Trocas

Kant, E. (1947). Idée d'une histoire universelle au point de vue cosmopolitique. In E. Kant, La philosophie de l'histoire. Paris: Aubier. (Trabalho original publicado em 1784)

Knight, F. (1959). Exchange. In Encyclopaedia of Social Sciences (Vols. 5-6, pp. 666669). New York: MacMillan.

Laplanche, J., \& Pontalis, J. B. (1988). Vocabulaire de Psychanalyse. Paris: PUF.

Marx, K. (1974). Salário, preço e lucro. In J. A. Giannotti (Org.), Karl Marx manuscritos econômico-filosóficos e outros textos escolhidos (pp. 55-99, Col. Os Pensadores). São Paulo: Abril Cultural. (Trabalho original publicado em 1865)

Mauss, M. (1974). Ensaio sobre a dádiva. Forma e razão da troca nas sociedades arcaicas. In M. Mauss, Sociologia e antropologia. São Paulo: Edusp. (Trabalho original publicado em 1908)

Meillassoux, C. (1985). Échange. In Encyclopaedia Universalis (Corpus 6, pp. 539544). Paris: Encyclopaedia Universalis France.

Perroux, F. (1960). Economia e sociedade: coação, troca, dom. São Paulo: Duas Cidades.

Santos, J. H. (1993). Trabalho e riqueza na fenomenologia do espírito de Hegel. São Paulo: Loyola.

Sartre, J.-P. (1960). Critique de la raison dialectique. Paris: Gallimard.

Tarot, C. (1993). Repères pour une histoire de la naissance de la grâce. In A. Caillé et al., Ce que donner veut dire. Paris: La Découverte.

Touraine, A. (1986). Conflits sociaux. In Encyclopaedia Universalis (Corpus 5, pp. 301-311). Paris: Encyclopaedia Universalis France.

Recebido em: 6.05.2006

Aceito em: 29.05.2006 